\title{
Can a questionnaire predict vitamin D status in postmenopausal women?
}

\author{
Andrea C Nabak' ${ }^{1}$ Rachael Erin Johnson ${ }^{2}$, Nicholas S Keuler ${ }^{3}$ and Karen E Hansen ${ }^{2, *}$ \\ 'University of Wisconsin Dietetics Program, Madison, WI, USA: ${ }^{2}$ Department of Medicine, University of \\ Wisconsin School of Medicine \& Public Health, Suite 4124 MFCB, 1685 Highland Avenue, Madison, WI \\ 53705-2281, USA: ${ }^{3}$ College of Agriculture \& Life Sciences, University of Wisconsin, Madison, WI, USA
}

Submitted 12 November 2012: Final revision received 2 May 2013: Accepted 13 June 2013: First published online 22 July 2013

\begin{abstract}
Objective: Our objective was to determine whether a questionnaire can identify individuals with vitamin D insufficiency (VDI).

Design: Women completed the Vitamin D \& Sun (VIDSUN) questionnaire and we measured their serum 25-hydrocyvitamin D (25(OH)D) levels. We assessed the sensitivity and specificity of the questionnaire to identify VDI (25(OH)D level $<50 \mathrm{nmol} / \mathrm{l}$ ).

Setting: Clinical Research Unit, University of Wisconsin-Madison.

Subjects: Postmenopausal women.

Results: We recruited 609 postmenopausal women with a mean age of 61 (SD 6 years), of whom 113 (19\%) had VDI. Women with VDI were more likely to be

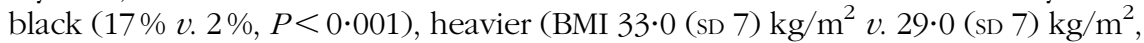
$P<0 \cdot 001)$ and less likely to tan in the past year (49\%v.72\%,P<0.001), use sunscreen $(57 \% v \cdot 72 \%, P<0 \cdot 001)$ or report sun exposure in the last 3 months. They consumed less vitamin D from supplements $(2 \cdot 15$ (sD 5.24) $\mu \mathrm{g} / \mathrm{d}$ (86 (SD 210) IU/d) $v \cdot 4 \cdot 55(\mathrm{sD} 8 \cdot 48) \mu \mathrm{g} / \mathrm{d}(188(\mathrm{sD} 344) \mathrm{IU} / \mathrm{d}), P=0 \cdot 003)$. In logistic regression models, black race, BMI, suntan within the past year, sun exposure in the past 3 months, sunscreen use and supplemental vitamin D intake were the most useful questions to identify VDI. From these six items, a composite score of $\leq 2 \cdot 25$ demonstrated $\geq 89 \%$ sensitivity but $\leq 35 \%$ specificity for VDI.

Conclusions: The VIDSUN questionnaire provides an initial tool to identify postmenopausal women at high or low risk of VDI. Existing studies suggest that inclusion of physical activity and TAG levels might improve the performance of the VIDSUN questionnaire.
\end{abstract}

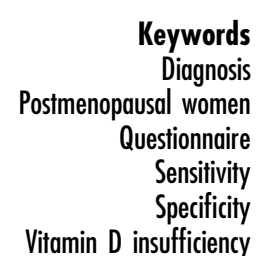

Low vitamin D levels are common in Americans, especially among postmenopausal women. Between 2000 and 2004 researchers in the Third National Health and Nutrition Examination Survey (NHANES III) measured serum 25hydroxyvitamin D (25(OH)D) levels in 20289 Americans using a RIA ${ }^{(1)}$. Vitamin D insufficiency (VDI), defined as a serum $25(\mathrm{OH}) \mathrm{D}$ level $<50 \mathrm{nmol} / \mathrm{l}$, was present in approximately $35 \%$ of adult women and $36 \%$ of women aged $50-69$ years $^{(1)}$. Such suboptimal vitamin D status can be attributed to limited sun exposure, reduced cutaneous vitamin D synthesis, poor nutrition, certain medications and diseases ${ }^{(2)}$. Individuals with suboptimal vitamin D status can experience decreased Ca absorption, which stimulates increased parathyroid hormone secretion. Parathyroid hormone promotes bone resorption to release skeletal $\mathrm{Ca}$ and maintain normocalcaemia, but over the long term secondary hyperthyroidism can contribute to decreased bone mineral density ${ }^{(3)}$.

Blood tests such as HPLC assays can diagnose low serum $25(\mathrm{OH}) \mathrm{D}$ levels, but at an expense of \$US 260 per test (personal communication with laboratory personnel at University of Wisconsin Hospital). Due to the high expense of vitamin D measurement, the Endocrine Society ${ }^{(4)}$ discourages population screening for suboptimal vitamin $\mathrm{D}$ levels. A questionnaire to identify people at high risk of VDI would potentially allow its detection prior to development of long-term consequences, such as osteoporosis or osteomalacia. While several studies have reported the variables that influence serum $25(\mathrm{OH}) \mathrm{D}$ levels, relatively few studies have designed a questionnaire and tested its sensitivity and specificity for detection of hypovitaminosis D.

Among 153 healthy women aged 18-41 years old living in Quebec, Canada who completed a questionnaire ${ }^{(5)}$, BMI, parathyroid hormone levels, travel south during the spring or winter, and use of oral contraceptives accounted for $40 \%$ of the variance in $25(\mathrm{OH}) \mathrm{D}$ levels. The paper did not report the sensitivity or specificity of the Quebec questionnaire. A 3 d food diary correlated weakly, but 
significantly $(r=0 \cdot 20, P=0 \cdot 04)$, with serum $25(\mathrm{OH}) \mathrm{D}$ levels among 165 ambulatory postmenopausal women living in the San Francisco Bay area ${ }^{(6)}$. A third chart review study $^{(7)}$ of 14920 veterans reported that TAG levels, race, season of vitamin D measurement, total cholesterol, BMI and serum $\mathrm{Ca}$ together accounted for $12 \%$ of the variance in serum $25(\mathrm{OH}) \mathrm{D}$ levels, with TAG accounting for almost $5 \%$ of the variance. The study did not identify a model that could predict either vitamin D levels or vitamin D status ${ }^{(7)}$ but notably did not assess participants' intake of vitamin D from supplements, diet or sun exposure. Among 3055 postmenopausal women participating in the Women's Health Initiative Study ${ }^{(8)}$, $21 \%$ of the variance in serum $25(\mathrm{OH}) \mathrm{D}$ levels was explained by vitamin D intake from food and supplements, waist circumference, exercise habits, race and latitude of residence. Unfortunately, a predictive model accurately identified vitamin D status in only 3\% with vitamin D deficiency, 64\% with VDI and 3\% with vitamin D sufficiency.

In a prior study, we tested the ability of a questionnaire to predict serum $25(\mathrm{OH}) \mathrm{D}$ levels in 184 healthy young adults aged 18-40 years living in Madison, Wisconsin ${ }^{(9)}$. Participants completed a questionnaire recording their age, gender, race/ethnicity, season of testing, sun exposure habits, use of multivitamins and vitamin D supplements, consumption of milk and cod-liver oil, and the presence of chronic intestinal disorders or diarrhoea. Three questions were moderately useful in identifying young adults with vitamin D deficiency, defined as a serum 25(OH)D level $<40 \mathrm{nmol} / \mathrm{l}$ : receipt of a suntan within the prior year, use of a tanning booth and consumption of $\geq 2$ glasses of milk daily. Overall, the questionnaire demonstrated a sensitivity of $79 \%$ and a specificity of $78 \%$ for vitamin D deficiency.

We hypothesized that a questionnaire could identify postmenopausal women with a higher likelihood of VDI. Our objectives were three-fold. First, we aimed to identify variables significantly associated with serum 25(OH)D levels as a continuous variable. Second, we aimed to identify a subset of variables that were independent and additive predictors of VDI. Third, we aimed to develop a short list of questions that, when answered as yes/no in a clinical setting, could generate a composite score to easily identify a person at high or low risk of VDI. We specifically avoided using laboratory tests as predictor variables, in order to minimize medical costs related to use of the questionnaire. We modified the previous questionnaire ${ }^{(9)}$ to record more specific questions regarding sun exposure, use of supplements and identification of skin type to test our hypothesis.

\section{Materials and methods}

We evaluated the performance characteristics of the Vitamin D \& Sun (VIDSUN) questionnaire (Table 1). We recruited postmenopausal women for a randomized, placebo-controlled clinical trial comparing the effects of different vitamin D doses on changes in Ca absorption, bone mineral density and muscle fitness (clinicaltrials.gov identifier NCT00933244). In order to participate in the study, women had to have a serum 25(OH)D level between 16 and $25 \mathrm{ng} / \mathrm{ml}$ and be $\geq 5$ years past the date of their last menses or bilateral oophorectomy, or $\geq 60$ years old if they received a hysterectomy without bilateral oophorectomy, with a total Ca intake (diet and supplements) of $\geq 600 \mathrm{mg}$ and $<1400 \mathrm{mg} / \mathrm{d}$. We excluded women $>75$ years old, those with inflammatory bowel disease, celiac sprue, chronic diarrhoea, hypercalcaemia, active cancer, nephrolithiasis or chronic kidney disease, defined as a glomerular filtration rate $<45 \mathrm{ml} / \mathrm{min}$ based on the Modification of Diet in Renal Disease formula ${ }^{(10)}$. We recruited potential participants by posting advertisements in local newspapers and by sending letters of invitation to the University of Wisconsin faculty and registrants of the University of Wisconsin's Institute of Aging Subject Registry. Women interested in the study contacted our office and were screened by telephone to determine eligibility for a screening visit.

Women who passed the telephone screen came to the University of Wisconsin Clinical Research Unit for a screening visit. At the visit, women provided a medical history and underwent phlebotomy for measurement of blood serum 25(OH)D levels using an HPLC assay. Research staff immediately centrifuged samples and removed serum for storage in a research freezer at $-70^{\circ} \mathrm{C}$ for up to 1 week, until analysis by HPLC assay. The assay has a lower limit of detection of $7 \mathrm{nmol} / 1$ and a betweenrun $\mathrm{CV}$ of $2 \cdot 6 \%$ to $4 \cdot 9 \%$ for $25(\mathrm{OH}) \mathrm{D}_{3}$ and $3 \cdot 2 \%$ to $12 \cdot 6 \%$ for $25(\mathrm{OH}) \mathrm{D}_{2}{ }^{(11)}$, with participation in the Vitamin D External Quality Assessment Scheme (DEQAS) to confirm accuracy of measurements.

At the screening visit, research nurses measured the participants' height using a single wall-mounted stadiometer and determined their weight without shoes using a single digital scale. At the visit, participants completed the VIDSUN questionnaire (Table 1). Participants completed the questionnaire by circling the answers that best reflected their habits. We modified the questionnaire from that used in the prior study ${ }^{(9)}$ by adding a Fitzpatrick score for skin type ${ }^{(12)}$ and asking additional information about the use of sunscreen, frequency of sun exposure, dose of vitamin D supplements and cod-liver oil consumed daily and presence of myalgia. Of note, participants were unaware of scores for each question. We include the point system in the questionnaire (Table 1) to indicate how to score the questionnaire.

\section{Ethics}

We obtained approval to conduct the study from the University of Wisconsin Human Subjects Committee, and participants gave written informed consent prior to any study procedures. 
Table 1 The Vitamin D \& Sun (VIDSUN) questionnaire

\begin{tabular}{|c|c|c|}
\hline Question & Answer & Score \\
\hline Height & $\mathrm{BMI} \leq 28 \cdot 0 \mathrm{~kg} / \mathrm{m}^{2}$ & $=1$ \\
\hline Weight & $\mathrm{BMI}>28 \cdot 0 \mathrm{~kg} / \mathrm{m}^{2}$ & $=0$ \\
\hline \multirow[t]{2}{*}{ Ethnic background } & Black & $=0$ \\
\hline & Other & $=1$ \\
\hline \multirow[t]{2}{*}{ Have you received a sun tan in the last 12 months? } & Yes & $=1$ \\
\hline & No & $=0$ \\
\hline \multirow{2}{*}{$\begin{array}{l}\text { In the last } 3 \text { months, how often were you in the } \\
\text { sunlight while lightly dressed? }\end{array}$} & Regularly & $=2$ \\
\hline & $\begin{array}{l}\text { Occasionally } \\
\text { Never }\end{array}$ & $\begin{array}{l}=1 \\
=0\end{array}$ \\
\hline \multirow{4}{*}{$\begin{array}{l}\text { How often do you apply sunscreen when going } \\
\text { outside? }\end{array}$} & Always & $=1$ \\
\hline & More often than not & $=0.75$ \\
\hline & $\begin{array}{l}\text { Sometimes } \\
\text { Infrequently }\end{array}$ & $\begin{array}{l}=0.5 \\
=0.25\end{array}$ \\
\hline & Never & $=0$ \\
\hline Do you take multivitamins? & $\begin{array}{l}\text { Yes. } \mu g(\text { IU) vitamin D: } \\
\text { No }\end{array}$ & $\leq 10 \mu \mathrm{g}(\leq 400 \mathrm{IU})=0$ \\
\hline \multirow[t]{2}{*}{ Do you take a vitamin D supplement? } & $\begin{array}{l}\text { Yes. } \mu g(\mathrm{IU}) \text { vitamin } \mathrm{D}: \\
\text { No }\end{array}$ & $>10 \mu \mathrm{g}(>400 \mathrm{IU})=1$ \\
\hline & Total $\mu \mathrm{g}(\mathrm{IU})$ vitamin $\mathrm{D}:$ & \\
\hline Do you use sunscreen? & $\begin{array}{l}\text { Yes. SPF: } \\
\text { No }\end{array}$ & \\
\hline $\begin{array}{l}\text { On average, how much sun exposure have you had } \\
\text { in the past week? }\end{array}$ & $\begin{array}{l}>30 \mathrm{~min} / \mathrm{d} \\
15-30 \mathrm{~min} / \mathrm{d} \\
5-15 \mathrm{~min} / \mathrm{d} \\
<5 \mathrm{~min} / \mathrm{d}\end{array}$ & \\
\hline Have you used a tanning booth in the last year? & $\begin{array}{l}\text { Yes } \\
\text { No }\end{array}$ & \\
\hline $\begin{array}{l}\text { How many servings of milk ( } 8 \text { ounces each) do you } \\
\text { drink daily? }\end{array}$ & Servings: & \\
\hline \multirow{3}{*}{$\begin{array}{l}\text { Do you take cod-liver oil or regularly eat fish such } \\
\text { as mackerel, salmon, catfish, or sardines? } \\
\text { Do you have frequent muscle aches? }\end{array}$} & $\begin{array}{l}\text { Yes. Servings/week } \\
\text { No }\end{array}$ & \\
\hline & Yes & \\
\hline & No & \\
\hline \multirow[t]{8}{*}{ Please circle the skin type that best describes you } & $\begin{array}{l}\text { Type I: white, very fair, red or blond hair, blue eyes, } \\
\text { freckles. Always burns, never tans }\end{array}$ & \\
\hline & Type II: white, fair, red or blond hair. Blue, hazel or & \\
\hline & $\begin{array}{l}\text { green eyes. Usually burns, tans with difficulty } \\
\text { Type III: cream white, fair with any eye or hair colour. }\end{array}$ & \\
\hline & Sometimes mildly burns, gradually tans & \\
\hline & Type IV: brown, typical Mediterranean Caucasian skin. & \\
\hline & Type V: dark brown, Middle-Eastern skin types. Very & \\
\hline & rarely burns, tans very easily & \\
\hline & Type VI: black. Never burns, tans very easily & \\
\hline
\end{tabular}

SPF, sun protection factor.

The participant undergoes height and weight measurement to determine BMI. The participant completes the questionnaire starting with self-identified race, circling the option that best reflects her habits. The scoring system is hidden from participants, but is recorded above to instruct users how to assign points for a total score of 0 to 7 . A final score of $\leq 2.25$ indicates higher likelihood of vitamin $D$ insufficiency.

\section{Statistics}

All data were entered in duplicate into an Excel ${ }^{\circledR}$ database and plotted to detect the presence of outliers and confirm a normal distribution. The following variables were analysed as potential predictors of vitamin D status: age, race, Fitzpatrick skin type, height, weight, BMI, season of vitamin D measurement, sun tan within the past year, use of sunscreen and tanning booths, recent sun exposure, habitual consumption of milk, fatty fish, cod-liver oil, multivitamins, vitamin D supplements, dose of vitamin D consumed from supplements and presence of myalgia.

We defined VDI as a serum 25(OH)D level $<50 \mathrm{nmol} / \mathrm{l}^{(13)}$, and then compared the characteristics of participants with and without VDI using the Wilcoxon test (continuous data) or the Fisher exact test (categorical data). We next used linear regression models to identify which of the variables analysed were significantly associated with serum $25(\mathrm{OH}) \mathrm{D}$ levels. We then used a backwards stepwise procedure to find the subset of variables that explained a large portion of the variability in serum 25(OH)D levels. From these stepwise models, we identified variables (answers to questions) that best discriminated between participants with and without VDI.

Finally, we identified the subset of questions that identified individuals at high or low risk of VDI. We used univariate logistic regression models to identify VIDSUN variables that were independent predictors of VDI. For significant variables that were continuous rather than dichotomous, we analysed their performance 
characteristics (sensitivity, specificity and area under the curve) to determine the best value at which the continuous variable predicted VDI. We arbitrarily scored risk factors for VDI as zero if present, so that lower total scores indicated lower 25(OH)D levels and a higher likelihood of VDI. We calculated each participant's composite score using the final significant variables. Lastly, we evaluated the composite score from all six variables to determine the threshold providing the best sensitivity and specificity for VDI.

We performed all analyses of data using $\mathrm{R}$ software version $2 \cdot 13 \cdot 1$. In all analyses, we used a $P$ value of $<0 \cdot 05$ as significant and we limited our model analyses to participants with no missing data.

\section{Results}

We analysed VIDSUN data from the first 609 participants who underwent a screening visit between March 2010 and May 2012, most of whom were Caucasian (90\%) with a mean age of 61 (SD 6 years), mean BMI of $29 \cdot 5$ (sD 6.8) $\mathrm{kg} / \mathrm{m}^{2}$ and mean serum 25(OH)D of $78(\mathrm{sD} 28) \mathrm{nmol} / \mathrm{l}$ (Table 2). Of the 609 participants, 113 (19\%) had VDI. Compared with participants who were vitamin $\mathrm{D}$ replete (Table 2), those with VDI were more likely to be black (17\% v. $2 \%, P<0.001)$ or have a Fitzpatrick skin type of V or VI. Participants with VDI had a higher BMI $(33 \cdot 0$ (SD 7) $\mathrm{kg} / \mathrm{m}^{2} v .29 \cdot 0(\mathrm{SD} 7) \mathrm{kg} / \mathrm{m}^{2}, P<0 \cdot 001$ ) and were less likely to undergo a study visit in summer (18\%v $v$. $29 \%, P=0 \cdot 015)$. Participants with VDI were less likely to take a multivitamin $(15 \% v .28 \%, P=0.005)$ or a vitamin $\mathrm{D}$ supplement $(18 \%$ v. 36\%, $P=0.002)$ and reported lower vitamin D intake from all supplements $(2 \cdot 15$ (SD $5 \cdot 24) \mu \mathrm{g} / \mathrm{d}(86(\mathrm{SD} 210) \mathrm{IU} / \mathrm{d}) v .4 .55$ (SD 8.48) $\mu \mathrm{g} / \mathrm{d}(188$ (sD 344) IU/d), $P=0 \cdot 003)$. Participants with VDI were less likely to apply sunscreen $(57 \% v .72 \%, P=0.003)$, have a suntan within the past year ( $49 \% v .72 \%, P<0 \cdot 001)$ or report regular sun exposure in the recent past.

Univariate associations between each variable and serum $25(\mathrm{OH})$ D levels are summarized in Table 3. Together, all variables accounted for $31 \%$ of the variance in serum $25(\mathrm{OH}) \mathrm{D}$ levels. In backwards stepwise selection, the final model explained $28.5 \%$ of the variance in serum $25(\mathrm{OH}) \mathrm{D}$ based on race, BMI, days to or from the autumn equinox, suntan in the past year, sun exposure in the past 3 months, use of multivitamins and vitamin D supplements and consumption of cod-liver oil $(P<0 \cdot 001)$.

In logistic regression models, we identified six variables that were independent and significant predictors of VDI. The six variables were black race (yes/no), BMI, vitamin D intake from supplements ( $\mu \mathrm{g} / \mathrm{d}(\mathrm{IU} / \mathrm{d}))$, suntan within the past year (yes/no), sun exposure in the prior 3 months (never, occasionally, regularly) and frequency of sunscreen use (spanning from never to always). BMI $<28.0 \mathrm{~kg} / \mathrm{m}^{2}$ and vitamin D intake $>10 \mu \mathrm{g} / \mathrm{d}(>400 \mathrm{IU} / \mathrm{d})$ were the thresholds at which a yes/no answer demonstrated the best sensitivity and specificity for VDI, with lower BMI and higher vitamin $\mathrm{D}$ intake each decreasing the probability of VDI. We further refined the scoring system for use of sunscreen and frequency of sun exposure (Table 1), so that weighting of these variables was congruent with weighting of the other four variables in the model.

We arbitrarily scored significant predictors of VDI as zero if present (Table 1) so that higher scores indicated a higher likelihood of vitamin D repletion. We added the scores for all six variables to determine a composite score for each participant. With this approach, a participant would have a composite score between 0 and 7 . For example, a participant with a BMI $>28 \cdot 0 \mathrm{~kg} / \mathrm{m}^{2}$, black race, vitamin $\mathrm{D}$ intake $<10 \mu \mathrm{g} / \mathrm{d}(<400 \mathrm{IU} / \mathrm{d})$, no tan within the prior year, rare sun exposure in the past 3 months and no use of sunscreen would have a VIDSUN score of 0 , indicating a high likelihood of VDI. Among 583 participants with no missing VIDSUN data, the six questions explained $21.5 \%$ of the variance in serum 25(OH)D levels.

Finally, we evaluated the composite score from all six variables to determine the threshold providing the best sensitivity and specificity for VDI (Table 4). A score of $\leq 2 \cdot 25$ provided $\geq 89 \%$ sensitivity for VDI, with a positive predictive value ranging from $82 \%$ to $86 \%$ but low specificity (35\%) and negative predictive value (41\%). Table 4 provides the sensitivity, specificity, positive and negative predictive values for composite VIDSUN scores between 0 and 7 . These results suggest that serum 25(OH)D measurement would be most useful and costeffective in postmenopausal women with a composite VIDSUN score of $\leq 2 \cdot 25$.

\section{Discussion}

We hypothesized that a questionnaire could identify postmenopausal women with a high or low likelihood of VDI. We developed the VIDSUN questionnaire and tested its performance characteristics in 609 postmenopausal women undergoing a screening visit for a large clinical trial, of whom 113 (19\%) had VDI. Six variables were independent and significant predictors of VDI: BMI, black race, vitamin D intake from supplements, sun tan within the prior year, sun exposure in the past 3 months and frequency of sunscreen application. Answers to the six questions provided a composite score for each participant and, subsequently, a score of $\leq 2 \cdot 25$ showed reasonable sensitivity and positive predictive value for VDI, although specificity was low. To our knowledge, ours is the first study to report the sensitivity and specificity of a questionnaire designed to identify VDI in postmenopausal women.

Our VIDSUN questionnaire identified several variables that were significant and independent predictors of VDI. In agreement with other researchers ${ }^{(14)}$, we identified sun 
Table 2 Demographic characteristics and questionnaire responses according to participants' 25-hydroxyvitamin D (25(OH)D) level: postmenopausal women attending a screening visit for a large clinical trial at the Clinical Research Unit, University of Wisconsin-Madison, March 2010 to May 2012

\begin{tabular}{|c|c|c|c|c|c|c|c|}
\hline \multirow[b]{2}{*}{ Characteristic } & \multicolumn{2}{|c|}{$\begin{array}{l}\text { All participants } \\
\quad(n \text { 609) }\end{array}$} & \multicolumn{2}{|c|}{$\begin{array}{c}25(\mathrm{OH}) \mathrm{D}<50 \mathrm{nmol} / \mathrm{l} \\
(n 113)\end{array}$} & \multicolumn{2}{|c|}{$\begin{array}{c}25(\mathrm{OH}) \mathrm{D} \geq 50 \mathrm{nmol} / \mathrm{l} \\
(n \text { 496) }\end{array}$} & \multirow[b]{2}{*}{$P$ value } \\
\hline & Mean or $n$ & SD or $\%$ & Mean or $n$ & SD or $\%$ & Mean or $n$ & SD or $\%$ & \\
\hline \multicolumn{8}{|l|}{ Demographics } \\
\hline Age (years)* & 61 & 6 & 60 & 6 & 61 & 6 & 0.223 \\
\hline \multicolumn{8}{|l|}{ Race/ethnicity (\%) } \\
\hline Asian & 8 & 1 & 3 & 3 & 5 & 1 & 0.342 \\
\hline Black & 30 & 5 & 19 & 17 & 11 & 2 & $<0.001$ \\
\hline Caucasian & 554 & 90 & 87 & 77 & 467 & 94 & $<0.001$ \\
\hline Hispanic & 7 & 1 & 2 & 2 & 5 & 1 & 0.767 \\
\hline Native American & 3 & 1 & 1 & $<1$ & 2 & $<1$ & 0.921 \\
\hline Multiple & 5 & 1 & 1 & $<1$ & 4 & 1 & $1 \cdot 000$ \\
\hline Other/no answer & 2 & $<1$ & 0 & 0 & 2 & $<1$ & 1.000 \\
\hline \multicolumn{8}{|l|}{ Skin type (\%) } \\
\hline I & 33 & 5 & 8 & 7 & 25 & 5 & 0.513 \\
\hline II & 121 & 20 & 24 & 21 & 97 & 20 & $0 \cdot 780$ \\
\hline III & 292 & 48 & 40 & 35 & 252 & 51 & 0.004 \\
\hline IV & 130 & 21 & 20 & 18 & 110 & 22 & 0.353 \\
\hline V & 22 & 4 & 13 & 12 & 9 & 2 & $<0.001$ \\
\hline VI & 10 & 2 & 8 & 7 & 2 & $<\overline{1}$ & $<0.001$ \\
\hline Not available & 1 & $<1$ & 0 & 0 & 1 & $<1$ & \\
\hline BMI $\left(\mathrm{kg} / \mathrm{m}^{2}\right)^{*}$ & $29 \cdot 5$ & $6 \cdot 8$ & 33 & 7 & 29 & 7 & $<0.001$ \\
\hline Serum 25(OH)D (nmol/l/)* & 78 & 28 & 37 & 10 & 85 & 23 & $<0.001$ \\
\hline \multicolumn{8}{|l|}{ Sun-seeking habits } \\
\hline \multicolumn{8}{|l|}{ Season of study visit (\%) } \\
\hline Spring & 192 & 32 & 39 & 35 & 153 & 31 & $0 \cdot 516$ \\
\hline Summer & 165 & 27 & 20 & 18 & 145 & 29 & 0.015 \\
\hline Autumn & 119 & 19 & 22 & 19 & 97 & 20 & $1 \cdot 000$ \\
\hline Winter & 133 & 22 & 32 & 28 & 101 & 20 & 0.090 \\
\hline Suntan within past 12 months (\%) & 413 & 68 & 55 & 49 & 358 & 72 & $<0.001$ \\
\hline \multicolumn{8}{|l|}{ Sunscreen use (\%) } \\
\hline Never & 184 & 30 & 48 & 42 & 136 & 27 & 0.003 \\
\hline Infrequently & 50 & 8 & 9 & 8 & 41 & 8 & $1 \cdot 000$ \\
\hline Sometimes & 155 & 25 & 31 & 27 & 124 & 25 & 0.670 \\
\hline Often & 148 & 24 & 18 & 16 & 130 & 26 & 0.025 \\
\hline Always & 64 & 11 & 6 & 5 & 58 & 12 & 0.056 \\
\hline Other/not available & 8 & 1 & 1 & 1 & 7 & 1 & 1.000 \\
\hline \multicolumn{8}{|l|}{ Sun exposure in past week (\%) } \\
\hline$<5 \mathrm{~min} / \mathrm{d}$ & 84 & 14 & 23 & 20 & 61 & 12 & 0.043 \\
\hline $5-15 \mathrm{~min} / \mathrm{d}$ & 146 & 24 & 35 & 31 & 111 & 22 & 0.075 \\
\hline $15-30 \mathrm{~min} / \mathrm{d}$ & 177 & 29 & 27 & 24 & 150 & 30 & 0.218 \\
\hline$>30 \mathrm{~min} / \mathrm{d}$ & 199 & 33 & 27 & 24 & 172 & 35 & 0.033 \\
\hline Other & 3 & $<1$ & 1 & 1 & 2 & $<1$ & \\
\hline \multicolumn{8}{|l|}{ Sun exposure in past 3 months (\%) } \\
\hline Never & 188 & 31 & 55 & 49 & 133 & 27 & $<0.001$ \\
\hline Occasionally & 292 & 48 & 47 & 42 & 245 & 49 & $0 \cdot 157$ \\
\hline Regularly & 124 & 20 & 9 & 8 & 115 & 23 & 0.002 \\
\hline No answer & 5 & $<1$ & 2 & 2 & 3 & 1 & $0 \cdot 318$ \\
\hline Use of tanning booth & 34 & 6 & 4 & 4 & 30 & 6 & $0 \cdot 420$ \\
\hline \multicolumn{8}{|l|}{ Vitamin D intake } \\
\hline Milk (servings/d)* & $1 \cdot 0$ & $1 \cdot 0$ & 0.9 & $1 \cdot 0$ & $1 \cdot 0$ & $1 \cdot 0$ & 0.071 \\
\hline Multivitamin use (\%) & 155 & 25 & 17 & 15 & 138 & 28 & 0.005 \\
\hline Vitamin D supplement use (\%) & 198 & 33 & 20 & 18 & 178 & 36 & 0.002 \\
\hline$\mu \mathrm{g} / \mathrm{d}$ from supplements ${ }^{*}$ & $4 \cdot 10$ & 8.03 & $2 \cdot 15$ & $5 \cdot 24$ & 4.55 & $8 \cdot 48$ & 0.003 \\
\hline IU/d from supplements* & 169 & 325 & 86 & 210 & 188 & 344 & 0.003 \\
\hline Cod-liver oil/fish use (\%)† & 206 & 34 & 31 & 28 & 175 & 36 & $0 \cdot 106$ \\
\hline
\end{tabular}

${ }^{*}$ These data are presented as mean and standard deviation; all other data are presented as number and percentage.

tOnly sixteen participants consumed cod-liver oil; their average dose was 3.6 tablespoons/week.

exposure as a significant predictor of serum $25(\mathrm{OH}) \mathrm{D}$ levels. In our study, three questions about sun-seeking habits (tan in the past year, regular sun exposure in the past 3 months and use of sunscreen) were independent predictors of vitamin D status. Unexpectedly, greater use of sunscreen was associated with higher serum $25(\mathrm{OH}) \mathrm{D}$ levels.
We believe this association simply reflects the fact that individuals who are outdoors often are more likely to use sunscreen, whereas individuals who never go outside will likewise never apply sunscreen.

In agreement with other studies ${ }^{(1,5,7)}$, we found that BMI was significantly associated with serum $25(\mathrm{OH}) \mathrm{D}$ levels. 
Table 3 Variables associated with serum 25-hydroxyvitamin D (25(OH)D) level among postmenopausal women ( $n$ 609) attending a screening visit for a large clinical trial at the Clinical Research Unit, University of Wisconsin-Madison, March 2010 to May 2012

\begin{tabular}{lrll}
\hline Characteristic & $P$ value & Multiple $R^{2}$ & Direction of association \\
\hline Demographics & & & \\
Age (years) & 0.365 & 0.001 & \\
BMl (kg/m ${ }^{2}$ & $<0.001$ & 0.081 & Higher with lower BMI \\
Skin type & 0.066 & 0.006 & \\
Race & $<0.001$ & 0.071 & Higher with less skin pigment \\
Days to or from autumn equinox & $<0.001$ & 0.050 & Higher near equinox \\
Sun-seeking habits & & \\
Season & $<0.001$ & 0.055 & Higher in summer and fall \\
Sunscreen use & 0.009 & 0.011 & Higher with greater sunscreen use \\
Sun protection factor & 0.028 & 0.008 & Higher with higher sun protection factor \\
Sunscreen adherence & 0.002 & 0.016 & Higher with greater sunscreen use \\
Sun in the past week & 0.001 & 0.017 & Higher with recent exposure \\
Sun in the past 3 months & $<0.001$ & 0.074 & Higher with recent exposure \\
Tanning booth use & 0.010 & 0.011 & Higher in tanning booth users \\
Tan within 12 months & $<0.001$ & 0.040 & Higher in those with tan \\
Vitamin D intake & & \\
Milk (servings/d) & 0.116 & 0.004 & Higher with use of supplement \\
Multivitamin use & $<0.001$ & 0.045 & Higher with use of supplement \\
Vitamin D supplement use & $<0.001$ & 0.073 & Higher as intake increased \\
Vitamin D intake from supplements $(\mu \mathrm{g} / \mathrm{d}(\mathrm{IU} / \mathrm{d}))$ & $<0.001$ & 0.032 & Higher as intake increased \\
Fish servings/week & 0.012 & 0.010 & Higher as intake increased \\
Cod-liver oil & 0.015 & 0.010 & \\
Myalgia & 0.051 & 0.006 & \\
\hline
\end{tabular}

Together all variables accounted for $31 \%$ of the variance in serum $25(\mathrm{OH}) \mathrm{D}$ levels. In stepwise backwards models, $28.5 \%$ of the variance was explained by race, BMI, days to or from the autumn equinox, suntan in the past year, sun exposure in the past 3 months, and consumption of multivitamins, vitamin $D$ supplements and cod-liver oil $(P<0 \cdot 001)$.

Table 4 Vitamin D \& Sun (VIDSUN) questionnaire composite score performance characteristics

\begin{tabular}{|c|c|c|c|c|}
\hline Score & Specificity & Sensitivity & Positive predictive value & Negative predictive value \\
\hline $7 \cdot 00$ & $1 \cdot 00$ & 0.00 & $1 \cdot 00$ & $0 \cdot 18$ \\
\hline $6 \cdot 75$ & $1 \cdot 00$ & 0.00 & $1 \cdot 00$ & $0 \cdot 18$ \\
\hline $6 \cdot 50$ & 1.00 & 0.01 & 1.00 & $0 \cdot 18$ \\
\hline $6 \cdot 00$ & $1 \cdot 00$ & 0.02 & $1 \cdot 00$ & $0 \cdot 19$ \\
\hline $5 \cdot 75$ & 1.00 & 0.07 & 1.00 & $0 \cdot 19$ \\
\hline $5 \cdot 50$ & 1.00 & $0 \cdot 10$ & 1.00 & 0.20 \\
\hline $5 \cdot 25$ & $1 \cdot 00$ & 0.11 & $1 \cdot 00$ & 0.20 \\
\hline $5 \cdot 00$ & 1.00 & $0 \cdot 18$ & 1.00 & $0 \cdot 21$ \\
\hline $4 \cdot 75$ & 0.97 & 0.27 & 0.98 & 0.23 \\
\hline $4 \cdot 50$ & 0.96 & 0.38 & 0.98 & 0.26 \\
\hline $4 \cdot 25$ & 0.95 & 0.40 & 0.97 & 0.26 \\
\hline $4 \cdot 00$ & 0.89 & 0.49 & 0.95 & 0.28 \\
\hline $3 \cdot 75$ & $0 \cdot 84$ & 0.56 & 0.94 & $0 \cdot 30$ \\
\hline $3 \cdot 50$ & $0 \cdot 76$ & 0.62 & 0.92 & 0.31 \\
\hline $3 \cdot 25$ & 0.75 & 0.65 & 0.92 & 0.33 \\
\hline $3 \cdot 00$ & 0.60 & 0.78 & 0.90 & 0.38 \\
\hline $2 \cdot 75$ & 0.56 & 0.82 & 0.89 & 0.41 \\
\hline $2 \cdot 50$ & 0.39 & 0.88 & 0.87 & 0.41 \\
\hline $2 \cdot 25$ & 0.35 & 0.89 & 0.86 & 0.41 \\
\hline $2 \cdot 00$ & $0 \cdot 17$ & 0.95 & 0.84 & 0.43 \\
\hline $1 \cdot 75$ & $0 \cdot 16$ & 0.96 & 0.84 & 0.47 \\
\hline $1 \cdot 50$ & $0 \cdot 13$ & 0.97 & 0.83 & 0.52 \\
\hline $1 \cdot 25$ & $0 \cdot 10$ & 0.98 & 0.83 & 0.52 \\
\hline 1.00 & 0.04 & $1 \cdot 00$ & 0.82 & 0.67 \\
\hline 0.75 & 0.03 & 1.00 & 0.82 & 0.60 \\
\hline 0 & 0.00 & 1.00 & 0.82 & $>0.60$ \\
\hline
\end{tabular}

BMI was one of four significant predictors of serum 25(OH)D levels in 153 healthy, ambulatory women aged 18-41 years in Quebec, Canada ${ }^{(5)}$. Among 14920 patients receiving care at six Veterans Affairs Medical Centers ${ }^{(7)}$, BMI explained $12 \%$ of the variance in $25(\mathrm{OH}) \mathrm{D}$ levels.
Likewise in 20289 Americans participating in NHANES III ${ }^{(1)}$, $25(\mathrm{OH}) \mathrm{D}$ levels were lowest in the obese, higher in the overweight and highest in the Americans with normal BMI. Earthman et $a l^{(15)}$ summarized the potential mechanisms by which obesity is associated with hypovitaminosis D, 
citing adipose tissue sequestration of fat-soluble vitamin D, greater 24-hydroxylase activity in adipose cells leading to greater catabolism of vitamin $\mathrm{D}$, and obesity-related fatty liver disease with lower 25-hydoxylation of precursors leading to lower $25(\mathrm{OH}) \mathrm{D}$ levels.

In our study, black race and skin type were significantly associated with VDI. Black race was an independent predictor of vitamin D status, functioning better than skin type to distinguish between women with and without VDI. Several other studies report that black race is a risk factor for VDI. Among 3055 women in the Women's Health Initiative study who underwent $25(\mathrm{OH}) \mathrm{D}$ measurement ${ }^{(8)}$, black women had significantly lower $25(\mathrm{OH}) \mathrm{D}$ levels and race was a significant variable in the model predicting $25(\mathrm{OH}) \mathrm{D}$ levels. Likewise, race accounted for almost $8 \%$ of the variance in $25(\mathrm{OH}) \mathrm{D}$ levels among 14920 patients in the Veterans Affairs study $^{(7)}$. Among 20289 Americans participating in NHANES III ${ }^{(1)}$, blacks had significantly lower 25(OH)D levels than Mexican Americans or whites. By reducing transmission of UV light, greater skin pigmentation is believed to protect races living near the equator from sun-induced vitamin D toxicity ${ }^{(16)}$. Melanin's effects on cutaneous synthesis of vitamin D was demonstrated by Clemens et al. $^{(17)}$. Serum 25(OH)D levels increased sixty-fold in Caucasian individuals after whole-body UV radiation $\left(0.054 \mathrm{~J} / \mathrm{cm}^{2}\right)$, whereas blacks receiving the same dose of UV radiation experienced no change in 25(OH)D levels ${ }^{(17)}$.

Scrutiny of prior publications might identify potential new variables to include, in attempts to improve the performance characteristics of the VIDSUN questionnaire. Inclusion of a food diary might improve the performance of the VIDSUN questionnaire ${ }^{(6)}$, although its use would be impractical in a clinical setting. Unfortunately, vitamin $\mathrm{D}$ intake based on the use of two FFQ did not correlate with 25(OH)D levels ${ }^{(6)}$, and answers to questions about consuming fish and milk in the VIDSUN questionnaire did not predict VDI. Physical activity was a significant predictor of serum 25(OH)D levels in 1984 adults in Auckland, New Zealand ${ }^{(18)}$. In agreement, recreational physical activity was a significant variable in models predicting $25(\mathrm{OH}) \mathrm{D}$ levels in the 3055 participants of the Women's Health Initiative ${ }^{(8)}$. Although physical activity might simply be a surrogate marker of sun exposure, its inclusion in future versions of the VIDSUN questionnaire would clarify whether exercise is an additional independent predictor of vitamin D status. Finally, cross-sectional studies report that higher vitamin D levels are associated with better lipid profiles, although vitamin D therapy does not improve the lipid profile ${ }^{(19)}$. TAG levels explained $5 \%$ of the variance in serum $25(\mathrm{OH}) \mathrm{D}$ levels in the Veterans Affairs study ${ }^{(7)}$. Measurement of TAG might improve the performance of the VIDSUN questionnaire.

Our study has several strengths. We tested the performance characteristics of the VIDSUN questionnaire in the first 609 women screened for a large clinical trial. We measured 25(OH)D levels using a highly accurate HPLC assay. Our findings are consistent with large epidemiological studies reporting that sun exposure, race and BMI predict vitamin D status. Our study also has limitations. We evaluated our questionnaire in postmenopausal women; we cannot assume it would predict vitamin D status in children, young adults or older men. Indeed, in our prior study ${ }^{(9)}$, vitamin D status in young adults was predicted by milk consumption, getting a suntan and use of tanning booths. We had a relatively small sample size that may have limited our power to detect associations between VDI and intake of certain foods, such as fatty fish. We suggest that future versions of the VIDSUN questionnaire ask about consumption of fish and cod-liver oil separately. Selection bias also limits our study. Individuals participating in research studies are more likely to be younger ${ }^{(20)}$, white ${ }^{(20)}$ and have a higher socio-economic status ${ }^{(21)}$ than individuals who do not participate in research. We recruited women from southern Wisconsin and certain racial groups were under-represented; a larger study with a more diverse population might identify other racial groups at high risk of VDI. We excluded individuals with significant chronic illnesses that might interfere with skeletal health or vitamin D status.

\section{Conclusion}

The VIDSUN questionnaire helped identify postmenopausal women with a higher likelihood of VDI. Revision of the questionnaire to include questions about exercise, TAG levels and consumption of vitamin D-rich foods such as fatty fish might improve its performance characteristics. Future studies are needed to refine and validate the questionnaire, with the goal of creating an inexpensive tool to aid clinicians in decisions to measure their patients' 25(OH)D levels.

\section{Acknowledgements}

Sources of funding: The work was supported by the National Institutes of Health (NIH) National Institute on Aging (AG028739), the Office of Dietary Supplements (AG028739) and an NIH Clinical and Translational Science Award Program (UL1TR000427). Conflicts of interest: K.E.H. is a consultant to Takeda Pharmaceuticals and Deltanoid Pharmaceuticals. All other authors have no conflicts of interest. Authors' contributions: K.E.H. designed and conducted the research study and had primary responsibility for the final content of the manuscript. K.E.H. and R.E.J. collected and entered data; all authors analysed the data, wrote the manuscript and approved the final manuscript. Acknowledgements: The authors thank the women for their participation in the study. 


\section{References}

1. Looker AC, Pfeiffer CM, Lacher DA et al. (2008) Serum 25hydroxyvitamin D status of the US population: 1988-1994 compared with 2000-2004. Am J Clin Nutr 88, 1519-1527.

2. Powell HS \& Greenberg D (2006) Tackling vitamin D deficiency. Postgrad Med 119, 25-30.

3. Dobnig H (2011) A review of the health consequences of the vitamin D deficiency pandemic. J Neurol Sci 311, 15-18.

4. Adams JS, Clemens TL, Parrish JA et al. (1982) Vitamin-D synthesis and metabolism after ultraviolet irradiation of normal and vitamin-D-deficient subjects. $N$ Engl J Med 306, 722-725.

5. Gagnon C, Baillargeon JP, Desmarais G et al. (2010) Prevalence and predictors of vitamin D insufficiency in women of reproductive age living in northern latitude. Eur $J$ Endocrinol 163, 819-824.

6. Hacker-Thompson A, Schloetter M \& Sellmeyer DE (2012) Validation of a dietary vitamin $\mathrm{D}$ questionnaire using multiple diet records and the Block 98 health habits and history questionnaire in healthy postmenopausal women in Northern California. J Acad Nutr Diet 112, 419-423.

7. Peiris AN, Bailey BA, Guha BN et al. (2011) Can a model predictive of vitamin D status be developed from common laboratory tests and demographic parameters? South Med J 104, 636-639.

8. Millen AE, Wactawski-Wende J, Pettinger M et al. (2010) Predictors of serum 25-hydroxyvitamin D concentrations among postmenopausal women: the Women's Health Initiative Calcium plus Vitamin D clinical trial. Am J Clin Nutr 91, 1324-1335.

9. Bolek-Berquist J, Elliot ME, Gangnon RE et al. (2009) Use of a questionnaire to assess vitamin D status in young adults. Public Health Nutr 12, 236-243.

10. Levey AS, de Jong PE, Coresh J et al. (2011) The definition, classification, and prognosis of chronic kidney disease: a KDIGO Controversies Conference report. Kidney Int $\mathbf{8 0}$, $17-28$.
11. Lensmeyer GL, Wiebe DA, Binkley N et al. (2006) HPLC method for 25-hydroxyvitamin D measurement: comparison with contemporary assays. Clin Chem 52, $1120-1126$.

12. Fitzpatrick TB (1988) The validity and practicality of sunreactive skin types I through VI. Arch Dermatol 124, 869-871.

13. Institute of Medicine, Food and Nutrition Board (2011) Dietary Reference Intakes for Calcium and Vitamin D. Washington, DC: The National Academies Press.

14. Brot C, Vestergaard P, Kolthoff N et al. (2001) Vitamin D status and its adequacy in healthy Danish perimenopausal women: relationships to dietary intake, sun exposure and serum parathyroid hormone. BrJ Nutr 86, Suppl. 1, S97-S103.

15. Earthman CP, Beckman LM, Masodkar K et al. (2012) The link between obesity and low circulating 25-hydroxyvitamin D concentrations: considerations and implications. Int J Obes (Lond) 36, 387-396.

16. Loomis WF (1967) Skin-pigment regulation of vitamin-D biosynthesis in man. Science 157, 501-506.

17. Clemens TL, Adams JS, Henderson SL et al. (1982) Increased skin pigment reduces the capacity of skin to synthesise vitamin $\mathrm{D}_{3}$. Lancet $\mathbf{1}, 74-76$.

18. Bolland MJ, Grey AB, Ames RW et al. (2006) Determinants of vitamin D status in older men living in a subtropical climate. Osteoporos Int 17, 1742-1748.

19. Ponda MP, Dowd K, Finkielstein D et al. (2012) The shortterm effects of vitamin D repletion on cholesterol: a randomized, placebo-controlled trial. Arterioscler Thromb Vasc Biol 32, 2510-2515.

20. Murthy VH, Krumholz HM \& Gross CP (2004) Participation in cancer clinical trials: race-, sex-, and age-based disparities. JAMA 291, 2720-2726.

21. Gross CP, Filardo G, Mayne ST et al. (2005) The impact of socioeconomic status and race on trial participation for older women with breast cancer. Cancer 103, 483-491. 